\title{
Autonomía y heteronomía *
}

\author{
CARMEN GONZÁLEZ MARÍN \\ Universidad Carlos III
}

RESUMEN. Este ensayo trata de la oposición autonomía/heteronomía, oposición que no es igual pero se asemeja a autonomía/autenticidad. Y su plausible deconstrucción es también paralela. Se examina la posibilidad de tomar la autonomía como aquello que presupone una forma de autenticidad o, en otros términos, el universalismo como un modo de contextualismo, desde el momento en que sólo leeremos o juzgaremos acciones como si todos tuvieran que hacerlo de la misma manera, porque - o cuando - pertenecemos a una comunidad de individuos autónomos, de universalistas. Por una parte, es necesario tratar de articular el universalismo como algo más que una expectativa optimista, y al mismo tiempo luchar contra el relativismo o el escepticismo. Si no queremos hacernos cargo de un argumento trascendental hemos de recurrir a algo mucho más modesto que habría que tratar de describir así: frente a una especie de transparencia de los contextos o a su carácter abierto, hemos de tender a cerrar los contextos, a considerarlos en su totalidad, con la adicional «falta de competencia» que otorga su opacidad -y la nuestra, incidentalmente - . Porque la transparencia del contexto es un derivado de la universalidad del juicio y recíprocamente. Ser un sujeto moral exige la plasticidad de actuar en contextos opacos y cargar con ello y sus consecuencias.
ABstract. This essay deals with the autonomy/heteronomy dichotomy, that is not equal but is alike the well known one autonomy/autenticity. And its plausible deconstrucción is also parallel. I examine the topic that the autonomy presupposes a form of autenticity or, in other terms, that universalism is also $a$ kind of contextualism, in a sense that we only will read or judge actions the same way, because - or when - we belong to a community of autonomous individuals, of universalists. On one hand, it is necessary trying to articulate universalism as something more than wishful thinking, and, at the same time, fighting against relativism or moral scepticism. If we do not want to have recourse to a transcendental argument, we have to think in much more modest terms, which would be necessary to describe this way: Opposite to a kind of transparency of the contexts or its opened character, we have to tend to close the contexts, to consider them as a whole, with the «lack of competence» that its opacity brings out - and our opacity, incidentally - Transparency derives from the universality of judgement, and conversely. To be a moral subject requires the plasticity to act in opaque contexts and to take in charge it and its consequences.

\footnotetext{
* Agradezco a Antonio Valdecantos la lectura de una versión inicial de este texto, aunque no sólo eso.
} 


\section{Introducción}

Parece un lugar común que no necesitaría de justificaciones que la autonomía es la principal característica de un sujeto interpretado en términos morales. No es plausible pensar la responsabilidad sin ella, de modo que la autonomía es la marca del sujeto moral, lo que lo diferencia de aquellos otros a quienes no podríamos nunca pedir explicaciones por sus acciones ni cargar con el peso de las mismas.

En no poca medida, la autonomía culmina un proceso, de demarcación a veces borrosa, en el que fundamentalmente el entorno y la educación permiten o fuerzan la adscripción de tal propiedad a quien antes no la poseía. Es la culminación del proceso de crecimiento de la persona. Tanto el niño como ciertos grupos humanos son educados o se autoeducan para ser sujetos a los que se puede y debe adscribir la propiedad de la autonomía. En todo caso, es razonable asumir que se precisa un aprendizaje para que se produzca la transición entre un ser no autónomo, aunque humano, y el sujeto autónomo. Es en este aprendizaje en el que naturalmente hemos de considerar la necesidad de lo que sólo podemos denominar «heteronomía».

Creo, y ésta es la idea central de este trabajo, que la tensión autonomía/heteronomía, implícita en el proceso mismo de «ganar» la autonomía, no sólo está plasmada efectivamente en esta genealogía del sujeto autónomo, sino que pervive siempre en el sujeto moral como una tensión constitutiva.

La buena prensa de la autonomía responde, entre otras cosas, a su respetable origen, y a la creencia «ilustrada» en una cierta «autosuficiencia», como marca del ser racional que somos. Sin embargo, al menos cierto modo de entender la autonomía es responsable de un modelo de individuo problemático, como de hecho así ha sido puesto de manifiesto desde diferentes puntos de vista. Si ese individuo nacido del concepto de autonomía es problemático, ciertamente no lo es menos el concepto mismo, al menos desde su formulación kantiana.

Mi objetivo en estas páginas es analizar esas dificultades a las que acabo de referirme y sus consecuencias (con vistas a una formación ética y al papel que la filosofía y, por qué, no la literatura desempeñan o pueden optar a desempeñar en tal proceso formativo). De ese análisis, y de la consideración de las dificultades y sus posibles vías de solución en el concepto y las consecuencias del concepto de autonomía, deberían surgir también las líneas maestras de un modelo de sujeto - moral - no específicamente fundado en la idea de autonomía como la otra e indisociable cara de la libertad. Un sujeto moral que no surja necesariamente del olvido de un supuesto concepto contradictorio de la autonomía, sino precisamente quizá de la tensión entre autonomía y heteronomía. Ahora bien, no podemos olvidar que el concepto de autonomía es central en las teorías universalistas, de modo que cualquier intento de ponerlo en tela de juicio determina también una revisión de las consecuencias a gran escala que de ello se sigan. De hecho, las críticas a los presupuestos del concepto de autonomía suelen esgrimirse desde ámbitos particularistas, como, por ejemplo, ciertas maneras de entender el feminismo.

\section{Dos rasgos del sujeto autónomo}

¿Cuándo decimos de un sujeto que es autónomo? La autonomía no se sigue necesariamente de la calidad de humano de alguien, y quizá ni siquiera se sigue de la capacidad de autogobernarse en la vida ordinaria - si atendemos a una diferenciación elemental entre autarquía y autonomía.

En «The importance of autonomy» ', Thomas E. Hill Jr. da cuenta de un problema que rodea el concepto de autonomía y 
que acarrea como consecuencia un malentendido que vale la pena despejar, al menos a su juicio. El malentendido es simplemente que una idea de autonomía, tal como la reconocemos desde la tradición ilustrada, es incompatible con otros conceptos morales de indiscutible interés, tales como compasión o cuidado. Una plausible manera de salvar el aparente carácter incompatible del concepto de autonomía y esos otros interesantes conceptos morales es, como propone Hill, afirmar que «autonomía» no posee un significado unívoco. Hill trata, pues, de dar con una salida, haciendo explícitas algunas de las acepciones del término «autonomía» y mostrando cómo acaso no responden a las expectativas que deberíamos desarrollar en torno a un concepto moral, mientras que otras, que sí lo hacen, son perfectamente compatibles con esos otros conceptos, tales como cuidado o compasión.

En primer lugar, y de acuerdo con una tradición reconocible como kantiana-rawlsiana, «autonomía» refiere a una propiedad de la voluntad de los adultos humanos, cuando se ven a sí mismos como legisladores morales prescribiéndose principios generales racionalmente, no motivados por determinismo alguno ni por deseos sensuales ${ }^{2}$.

Los aspectos fundamentales que caracterizan esta versión de autonomía son claramente el carácter desinteresado del sujeto autónomo, es decir, su desligamiento de las contingencias puntuales, cosa que se presenta bajo el aspecto de la abstracción de las diferencias personales o, en términos rawlsianos, el velo de ignorancia. La segunda característica es que ese concepto de autonomía se aplica cuando el sujeto se interpreta en su rol de legislador - es decir, en un rol que implica pasar revista a algo, reflexionar y tomar decisiones - . Naturalmente la necesidad de abstraer las contingencias tiene su formulación en la exigencia de imparcialidad. Sin embargo, como señala Hill razonablemen- te, el concepto de imparcialidad no es necesario en términos absolutos - es decir, no es acaso deseable siempre ser imparcial, en el sentido de ciego a las circunstancias y los contextos concretos-, sino que forma parte del entramado más complejo del análisis de los problemas morales. Hay un estrato del análisis en que es precisa esa imparcialidad, sin embargo, situarla en el inicio de ese análisis puede cegarnos ante sus implicaciones, como de hecho ocurre.

Ahora bien, cuáles sean las razones por las que se ha construido este concepto de autonomía merecerían una reflexión más profunda que pospongo por el momento. Lo que es evidente es que el sujeto en que piensa Kant, en su esquema, posee un verdadero yo que es abstracto $e$ imparcial por ello ${ }^{3}$, dado que carece de determinaciones; pero es dudoso que esa imparcialidad que se termina entendiendo como la existencia de un solo punto de vista sea efectivamente deseable.

$\mathrm{Si}$, en esta primera acepción, «autonomía» refiere a una propiedad del sujeto moral o de su voluntad, en una segunda acepción, «autonomía» viene a identificarse con un derecho a que se hace acreedora toda persona responsable, y que podríamos explicar como el respeto a la libertad de elección o la no-interferencia. Si pensar el sujeto autónomo como desinteresado e imparcial nos impide pensarlo como sensible a las necesidades particulares, pensar en la autonomía como un derecho hace también difícil pensar en un sujeto compasivo o cuidadoso. Dado que en el ánimo de Hill no parece estar otra cosa que presentar una idea de autonomía «más limitada» - quizá habría que calificarla de «menos» limitada, más bien-, su carga argumental consiste en eliminar parte de las aparentes implicaciones «extremas» de la idea de autonomía como un «derecho»; en hacernos saber, en suma, que sostener la idea de autonomía «no significa que las personas son mejores moralmente, o que se hallan en un estadio 
de desarrollo más elevado, si piensan constantemente en problemas morales como conflictos entre derechos individuales, en lugar de percibirlos como ocasiones para mostrar sensibilidad y compasión» 4 .

Ni la autosuficiencia ni la imparcialidad son en realidad objetivos morales ni tienen necesariamente que ver con lo moral, probablemente; no nos hablan - podemos en esto estar de acuerdo con Hillde una condición suficiente de un sujeto moral. Su noción «más limitada» de autonomía apuesta por un sujeto autogobernado, no ciego, ni movido por impulsos neuróticos o prejuicios, y específicamente no fracturado o auto-fracturado. La sensibilidad al contexto ha de ser una característica que debe coexistir con la capacidad de percibir las situaciones concretas, sin distorsionarlas por lo moralmente irrelevante. En resumidas cuentas, este agente moral «más limitadamente» autónomo ha de regirse por «principios y valores que responderán a consideraciones genuinas y no serán epifenómenos no relacionados con las motivaciones morales», y asimismo ha de ser alguien que no se autoengaña. Es decir, la «nueva» noción de autonomía recoge, en resumidas cuentas, una de las propiedades sustanciales del «viejo» concepto, la unidad interna del sujeto.

$\mathrm{Si}$, por otra parte, repasamos las descripciones del sujeto autónomo que nos proporciona Gerald Dworkin, observamos una característica que hemos de sumar a la específicamente mencionada anteriormente «no autofractura». Gerald Dworkin en The Theory and Practice of Autonomy ${ }^{5}$ enumera un conjunto de descripciones de lo que significa para un sujeto ser autónomo, según las tradiciones en que se utiliza el concepto de autonomía. Son las siguientes, como explicación de una definición previa de autonomía moral:

- Una persona es moralmente autónoma si, y sólo si, sus principios morales son en efecto suyos.
- Una persona es moralmente autónoma si, y sólo si, es la autora de sus principios morales.

- Si, y sólo si, elige sus principios morales.

- Si, y sólo si, su voluntad es la fuente última de sus principios morales.

- Si, y sólo si, decide qué principios morales acepta como ataduras.

- Si, y sólo si, lleva la responsabilidad por la teoría moral y los principios que aplica.

- Si, y sólo si, rechaza aceptar a otros como autoridades morales, si no acepta sin consideración independiente el juicio de otros sobre lo que es correcto moralmente.

En este conjunto de descripciones, que responden a una idea de autonomía como una propiedad del sujeto moral, no cabe duda de que destaca la fuerza del posesivo, que nos lleva a interrogarnos acerca una segunda característica que viene a sumarse a la ya señalada más arriba - la unidad, la no autofractura - . ¿Es preciso el autoconocimiento, la autotransparencia, para pensar al sujeto como autónomo? Parece que la respuesta ha de ser afirmativa; de lo contrario, es difícil entender cómo el sujeto sería capaz de advertir que los principios por los que se rige son efectivamente los suyos.

No cabe duda de que sin necesidad de adoptar posiciones postmodernas, ninguna de las dos características del sujeto moral que priman en estas versiones es en absoluto autoevidente. La no fragmentación interna y la transparencia vienen a incidir sobre la misma necesidad perentoria de auto-conocimiento y autocontrol que me gustaría a continuación analizar brevemente. Por otra parte, la abstracción de las determinaciones concretas y ausencia de fracturas internas parecen presuponer alguna forma de internalismo, o van en la dirección de hacerlo como remedio ante los peligros del escepticismo y el desorden 
moral. Contra tal amenaza el internalismo garantiza la continuidad entre la intención, la acción y el juicio ${ }^{6}$.

No es, sin embargo, posible abogar por el internalismo si no postulamos antes un cierto tipo de sujeto; y éste no puede ser otro que el sujeto unitario y no sometido a las determinaciones de lo contingente. ¿Por qué he de postular este sujeto y no otro? Porque de no ser así las cosas es difícil aceptar sin más que mis motivaciones internas para actuar de cierto modo sean efectivamente tales - i. e., motivaciones reales, internas y mías - . Es efectivamente difícil sostener que los principios que acepto y juzgo adecuados, y en consecuencia los principios por los que me guío sean efectivamente universales, podría estar aquejado de alguna neurosis o dejarme vencer por el prejuicio o por emociones distorsionadoras que me confundiesen.

Por supuesto, hay que interpretar en su justa medida lo que se esconde tras estas «necesidades» de postular un tipo de sujeto y una versión internalista al mismo tiempo. Hay, a mi juicio, dos tipos de creencias, una metafísica y otra meta-ética, que confluyen en un mismo punto y determinan estas versiones. Por una parte, la creencia que se podría formular así: «Sólo desde la abstracción es posible alcanzar algo universal», lo cual aparentemente se aproxima al terreno de la tautología. Evidentemente si establecemos la ecuación concreto/abstracto y particular/universal ingresamos en el territorio de la tautología. Sin embargo, lo que realmente significa este enunciado es que sólo lo abstracto es inteligible, y ello, a su vez, que sólo lo desligado de las contingencias «mundanas» es inteligible. En segundo lugar, y de manera clara, la buena actuación moral se asimila con la transparencia y la simplicidad - la unidad - de las motivaciones internas - es decir, la adherencia, la unidad, de la voluntad a o con la ley moral- .

La respuesta a la pregunta que abría este apartado - «qqué hace de un sujeto un sujeto autónomo?»- no es, en definitiva, otra que la unidad interna del yo, la no autofractura, la abstracción de las contingencias que es condición de la trasparencia interna. Nótese que ambas propiedades nos hacen pensar sin duda en el miedo al error - a la ausencia de certeza-.

\section{El miedo a errar y el aprendizaje}

Es la dificultad lo que hace que la deliberación moral se sustituya o se suplante por la aceptación y el seguimiento de normas, como es obvio. Y es esa dificultad, asimismo, la que nos exige hacer rígidas las reglas $-\mathrm{y}$ lo que seguidamente pervierte el mundo moral-. Éste es el peligro inminente de ciertos procedimientos para el aprendizaje moral en su búsqueda por evitar el error ${ }^{7}$. Podría pensarse que el mismo miedo a errar que ha obligado a nuestra tradición filosófica a construir una imagen del sujeto autónomo como un sujeto sin fisuras es el que podría acabar por hacerlo caer en la más indeseable forma de heteronomía y asi hará colapsar la oposición autonomía/heteronomía.

El miedo al error podría plausiblemente explicar la necesidad de postular una unidad interna y una continuidad entre el juicio y la motivación para la acción. Pero si analizamos detenidamente lo que ello significa, probablemente llegaremos a un callejón sin salida. Pensemos en el siguiente ejemplo. Alguien realiza una acción altruista, por ejemplo, acoge a un niño, al que cuida y educa con todo esmero y de modo intachable. Desde un punto de vista ético no podríamos sino aprobar tal conducta. Pero imaginemos que este sujeto que así se comporta no tiene como motivación para su acción otra que agradar a alguien en quien aspira a despertar amor. Nada en la conducta de este sujeto, ni siquiera en estas motivaciones es ilegítimo, o moralmente reprobable en principio. Sin embargo, es probable que el valor moral de su conducta altruista quede al 
menos nublado por el hecho de que las motivaciones de la misma no son «continuas» con ella. Ésta es la razón, creo, por la que se suele pensar en términos internalistas o de unidad o integridad del sujeto, como si la posibilidad de fisuras entre las motivaciones del sujeto y sus acciones contaminase a las acciones mismas. Una acción «buena» termina por no serlo cuando las motivaciones no son «rectas».

Ahora bien, pensemos en el caso inverso. No me refiero desde luego al caso en que las motivaciones y la acción son continuas pero son moralmente «malas», sino más bien a algo un poco más interesante. La cuestión es si la buena motivación convierte a la acción en buena, si se da una simetría perfecta entre el caso en que la acción buena no está acompañada de intenciones rectas y el caso en que las intenciones rectas no son seguidas por acciones buenas. La respuesta, creo, es que tal simetría no se da. Una motivación «no recta» determina un juicio negativo, mientas que una acción «no buena» no lo hace necesariamente - es probable que encontremos disculpas cuando el sujeto actuó con buena voluntad, disculpas que no encontramos cuando la acción era «buena» pero la voluntad no era «recta»-. Es chocante, adicionalmente, que sean así las cosas, dado que ello nos conduce necesariamente a postular alguna forma de relativismo. Así se hace necesario postular la inseparabilidad de la buena voluntad y la ley moral de carácter universal. De modo que nuestras acciones quedan «atenazadas» por la continuidad entre la motivación y la acción, por una parte, y por la universalidad de la ley que hace «plausible» postular unas motivaciones y no otras, por la otra.

En resumen, podemos reconstruir el argumento del siguiente modo: el miedo al error o, en otros términos, el escepticismo, el temor a no estar seguro acerca de la adecuación de las acciones o la validez de los juicios morales presenta un doble $\mathrm{e}$ interesante frente. Por una parte, la sospecha acerca del carácter erróneo del juicio acerca de ciertas acciones o conductas; por la otra, la sospecha acerca del posible error al juzgar a los sujetos que las ejecutan. Es decir, el escepticismo se hace presente como una amenaza en el momento en que somos conscientes de que juzgamos como «buenos» a ciertos sujetos que ejecutan acciones «malas» -y ello es así desde el momento en que disculpamos, etc. - . Es decir, en el momento en que somos conscientes de la distancia entre el sujeto y sus acciones (pero esa percepción nos lleva a un territorio indeseable demarcado por el viejo dilema de Eutifrón: no podemos estar seguros de si una acción es buena porque el sujeto es bueno o si los sujetos son buenos cuando llevan a cabo buenas acciones).

Quizá una resistencia, comprensible por lo demás en la tradición filosófica, a hacerse eco de la imposibilidad de explicar la aplicación de predicados como «es bueno» o «es malo» en términos absolutos, tal como la señalara Wittgenstein ${ }^{8}$, es, en definitiva, responsable de la construcción de un tipo de sujeto que pasa por ser el caso estándar o paradigmático en la reflexión moral, y cuya característica fundamental es la ausencia de fisuras.

En La tentación de la inocencia ${ }^{9}$ Bruckner sostiene que el nacimiento del sujeto moderno ilustrado viene lastrado por el concepto de culpa. Su presentación del caso Rousseau como ejemplo más característico es desde luego de lo más significativo. La ansiedad de Rousseau por la excusa responde a su autointerpretación como necesariamente abocado a la culpa. El sujeto moderno es culpable porque ha de elegir y equivocarse, y su culpa - que en el fondo es otro nombre de su libertad o de su autonomía - lo convierte en un sujeto dividido auto fragmentado (no me interesa tanto la conclusión que para los tiempos presentes pueda tener el libro de Bruckner - nuestra sempiterna vocación 
por manifestarnos como «infantes inocentes», como un procedimiento de convocar el «perdón» y la manifestación pública de nuestra unicidad - , sino más bien las consecuencias que la descarnada versión rousseauniana va a tener en la ética, $i . e .$, a mi juicio, la idea kantiana de autonomía). Podría decirse que el sujeto moral kantiano ha de ser abstracto para no caer en la desunión y la quiebra interna; de este modo se establece una separación radical entre lo psicológico y lo moral, y lo primero queda fuera del espectro de interés del filósofo moral ${ }^{10}$,

En la huida del error, de la incertidumbre, que se presenta marcada por la señal del error automáticamente, nuestra tradición ha descubierto, al menos desde San Agustín, el "castillo interior» " donde la certeza y el Bien Supremo en ese caso son la misma cosa, y ya no desea quitar los ojos de él. Por ello se construye ese sujeto sin fisuras, al que convierto en sujeto responsable exclusivamente porque es un sujeto sin fisuras, de modo que le atribuyo una perfecta continuidad entre juicios morales, motivaciones morales y acciones, y cada vez que esto no se da de este modo, lo juzgo como «malo». Así excluyo todos los casos dudosos, todos aquellos en que la distancia entre el juicio y la motivación, o entre ésta y la acción, me plantean dudas.

La mala prensa de la heteronomía es un derivado de este tipo de postulación de la autonomía de la voluntad como la otra cara de un sujeto que se rige por la ley moral, y de su contraria - la heteronomía - como ligada a máximas morales ilegítimas. Autonomía y ley moral son las dos caras de una misma moneda, $y$, en términos generales, el pleonasmo «sujeto moral autónomo» da a entender, precisa mente por su calidad de pleonasmo, que ser un sujeto moral es ser moralmente «bueno». Por ello, lo que sale del límite del pleonasmo, por ejemplo, «sujeto moral heterónomo", no cabe en la categoría de lo moral o de lo moralmente «bueno».
El optimismo kantiano se fundaba en el principio de la dignidad humana; $y$, al parecer, cualquier intento de separar o deslindar tal principio y la versión estándar de la autonomía pasa por ser un atentado contra ella, y, naturalmente, contra la libertad humana. «La contingencia, la casualidad, parece ser uno de los peores enemigos de la libertad y dignidad del ser humano», escribe Odo Marquand ${ }^{12}$. Ciertamente, son la contingencia y la casualidad no los enemigos de la libertad y dignidad humana necesariamente, pero sí de un cierto modo de entender al sujeto moral. La autonomía es una propiedad de los seres racionales que se liga a su autogobierno y su autolegislación, y esa postulación trascendental sirve siempre como desideratum del valor de las máximas morales, es decir, como deseo de la no contingencia de lo humano.

El aprendizaje en todos los ámbitos está destinado a arrancarnos del error. Cuando se trata de cuestiones morales $-y$ creo que no sólo en esos casos- no es satisfactorio sin más el hecho de no errar, sino solamente el de no errar a sabiendas de que no se yerra, es decir, exigimos la conciencia de no estar errando, por tanto, el conocimiento de lo que hay y no hay que hacer. En otras palabras, un sujeto que nunca cometiese errores, de ningún tipo, pero que al mismo tiempo fuese incapaz de explicar por qué su comportamiento es correcto, probablemente no sería un buen candidato a sujeto moral, sino que lo tomaríamos por un autómata o algo por el estilo. Naturalmente las razones por las que juzgaríamos de ese modo a este posible sujeto infalible no son su carácter infalible, sino su falta de conciencia de las razones de sus actos. En otras palabras, el obrar a instancias de algo externo a sí mismo, el hecho de no ser autónomo. El comportamiento heterónomo, trivialmente como marca de la ausencia de autonomía, incapacita para convertirse en candidato a sujeto moral. 
¿Qué hay de malo en no ser autónomo? Al parecer todo, pero específicamente el ser manejable, el estar a expensas de otro u otros, o de las circunstancias simplemente, en una palabra, la plausible carencia de firmeza y unidad.

Aprender es ejercitarse para sortear los peligros del error. Ahora bien, el aprendizaje es cuestión de imitación o por el contrario responde a la internalización/ seguimiento de reglas o principios. Pero quizá lo que podríamos considerar común a cualquier modelo de aprendizaje moral específicamente es que, en todos los casos, se trata de constituir un sujeto, una identidad no quebrada, no desgarrada, sin fisuras, y que, por ello, cualquier ruptura o desgarro se interpreta como deficiencia. El aprendizaje, especialmente cuando se trata de aprendizaje moral, pero no sólo moral, está destinado a asegurarnos una acción correcta, o cursos de acción correctos, o al menos una percepción correcta de los cursos de acción propios y ajenos. Y hay que poner el énfasis en el término «asegurarnos", porque todo aprendizaje ha de estar consagrado a conducirnos a la certeza o a algún tipo de certeza acerca de algo; a eso lo denominamos ser competentes, precisamente. Lo que ocurre es que ser competente o estar seguro en moral suele implicar o permite al menos ser traducido, en términos internalistas, como ser un sujeto en el que advertimos una continuidad o contigüidad entre las motivaciones para la acción y la acción misma. De modo que toda ruptura se interpreta como una deficiencia ${ }^{13}$.

Tenemos muchos y, creo, variados ejemplos que contribuyen a sostener lo que acabo de indicar. Probablemente no hay un caso más claro que la historia de la duplicidad Jekill/Hyde, como manifestación del carácter destructivo de la ruptura interna. Pero, igualmente, la misoginia estándar nos ofrece buenos ejemplos de la maldad representada como falta de unidad interior, a imagen y semejanza de las ver- siones aristotélicas del malo, por ejemplo en su teoría de la amistad. Cualquier instrumento que podamos utilizar en el pro ceso de aprendizaje ha de estar diseñado precisamente para lograr esa unidad que podría suponerse en entredicho. Si bien es tema para otro momento, podríamos tratar de enunciar simplemente cómo es plausible reconstruir los pasos que determinan la necesidad de la unidad como condición del sujeto moral. Parece razonable pensar que ello es así simplemente porque la identidad no puede entenderse en términos diferentes de la unidad interna, y que sólo podemos hablar de un sujeto moral si asumimos su identidad, o que ésta es la garantía de su carácter moral, en suma ${ }^{14}$.

\section{Revisando la noción de autonomía}

Hasta ahora, he tratado de argumentar que la noción de autonomía, entendida bajo las especies de integridad, o unidad interna, y de autotransparencia, es necesaria como herramienta para luchar contra el error $o$, en suma, para alcanzar la certeza. Quizá es el momento de intentar aportar argumentos que hagan más explícito dónde se hallan las quiebras de esa noción, interpretada en los términos en que la hemos definido. Creo plausible elaborar un tipo de argumento que podríamos denominar «pragmático», dado que se asienta en el modo en que atribuimos la autonomía a los otros. El argumento podría hacerse explícito aproximadamente así: la atribución de autonomía se realiza desde la nuestra propia, de modo que o bien incurrimos en circularidad, o es implausible que podamos efectivamente atribuirla a otros.

Es, al parecer, imprescindible sostener una idea de autonomía en la que todo movimiento de adscripción o atribución al otro esté definido desde la mía propia; de lo contrario, el carácter universal de mis leyes morales es imposible de sostener. Debo abstraer lo que diferencia tanto co- 
mo para ponerlo en tela de juicio; de modo que la segunda cara de este argumento ha de elaborarse a partir de la manera de responder a las demandas del otro. Desde el punto de vista del sujeto que atribuye autonomía a otro - semejante al punto de vista de quien responde moralmente a otro-, éste ha de realizar un argumento transcendental en cierto modo - que así evita o borra las diferencias que hacen implausible el movimiento de ponerse en el lugar del otro-.

$\mathrm{Si}$, contemplado desde el punto de vista del sujeto, la autonomía está lastrada de algunos problemas, particularmente del internalismo, cuando contemplamos el concepto de autonomía como algo que atribuimos al otro los problemas no son menores. Desde luego no atribuimos autonomía a cualquier ser humano ni siquiera. Y la no atribución de autonomía es condición suficiente (al parecer) para hacerle decaer de algunas obligaciones y derechos igualmente. Pero forzosamente hemos de sospechar que estamos sometidos a cierta circularidad en nuestros procesos de atribución de autonomía. Me explicaré con la ayuda de un ejemplo conocido, por otra parte, en las discusiones de bioética. El caso de Baby Doe.

Una pareja tuvo un hijo con síndrome de Down, y con un problema físico adicional que le impedía ingerir alimentos. Los padres no deseaban criar a un ser con deficiencias graves, y los tribunales aceptaron su alegación, de modo que se decidió no realizar la intervención quirúrgica necesaria ni alimentar artificialmente al recién nacido y se le dejó morir. Me interesa ahora solamente el tipo de argumento que pudo ser utilizado para respaldar la opción de los padres de no intervenir quirúrgicamente al bebé, es decir, de no llevar a cabo ninguna acción para prolongarle la vida. ¿Como se podría reconstruir ese tipo de argumento en nuestros términos?

La manera de atribuir autonomía al otro es el movimiento de ponerse en su lugar; de este modo, además sabemos lo que el otro puede y debe considerar adecuado y rechazable, y somos capaces de responder ante ello. Hemos de suponer que si Baby Doe fuera capaz de decidir, realizando el movimiento, no estimaría que la decisión habría de ser otra que la que tomaron los tribunales y los padres. No obstante, si pudiera tomar tal decisión no sería legítimo no proporcionarle los cuidados requeridos. Dado que asumo que no podría jamás tomar ninguna decisión, que es un otro inconmensurable en cierto modo, es improbable que pueda captar cuáles son sus necesidades, etc., poniéndome en su lugar. Si asumo la validez de este ponerse en el lugar del otro, en el fondo estoy aceptando un contrafáctico del tipo «si pudiera decidir, decidiría lo mismo que yo -y mi decisión sería un reflejo de la suya»-. Pero si así fuese yo no podría decidir que no es digno de recibir el tipo de cuidados necesarios para seguir adelante con su vida, porque carece de las cualificaciones humanas necesarias, esto es, de su autonomía entre otras.

Esto significa que hay una brecha difícil de salvar en el modo en que acostumbramos a tratar de entender al otro atribuyéndole autonomía (como si nuestra única forma de hacerlo no fuera acercarse al otro, sino traer al otro a mi terreno exclusivamente, $y$ en la medida en que no casa con mis particularidades, excluirlo).

De cualquier forma, hay que insistir en que la manera de superar la acusación de abstracción para las posiciones universalistas es sostener que éstas requieren, en todo caso, el movimiento que se define como «ponerse en lugar del otro». Cuando pienso que responder a quien demanda justicia exige ponerme en su lugar, si estoy asumiendo un principio de empatía, el problema es inmediato: o bien tal empatía es implausible (al menos lo es en algunos o muchos casos); o, si se da, parece más bien que me disuelvo en el otro o más 
bien que el otro se disuelve en mí, se hace como yo. Sólo asumo la demanda del otro cuando es o puede ser como yo. Es quizá «ilegítimo», no obstante, abstraer del otro todo aquello que lo separa de mí y que hace implausible que me ponga en sus zapatos, porque eso es justamente lo que lo hace otro.

Parece un rescoldo de lo que llamaría el perjuicio parmenideano, unido a un prejuicio sentimental: por una parte, no puedo comprender excepto aquello que podría formar parte de mí, con lo que podría estar en comunión; por otra, no puedo comprender intelectualmente sino aquello que es idéntico a mí - porque pensar y ser es lo mismo-

Pero la demanda de la justicia probablemente es algo diferente de la exigencia de respuesta a lo que podrían ser mis propias demandas. Es quizá la de responder a ciertas demandas que ni siquiera comprendo bien - por ello no puedo ni calcular, ni tomar una decisión con certeza-. En realidad, frente a una noción problemática de autonomía, la heteronomía es, de facto, sólo la consecuencia práctica de la opacidad del otro.

En resumen, contra el argumento general que nos dicta que la respuesta al otro es un derivado de mi percepción de que el otro se sentiría razonablemente compelido a hacer lo mismo, y a sostener que todos aquellos a los que se atribuye autonomía lo harían también, podríamos plausiblemente objetar un problema «interno» a la noción misma de autonomía en esos términos, como sigue: La autonomía nos previene del error - al universalizar las razones para la acción-. Pero, de hecho, la autonomía debería permitirme equivocar$m e-\mathrm{y}$ no sólo en mis prácticas, sino en mis juicios y cargar con el error-, si no es así, resulto siempre justificado por la universalidad de las normas, que es, por otra parte, no un hecho, sino una declaración, y eso paradójicamente es una forma de heteronomía.
Adicionalmente, a este argumento impertinente podríamos añadir un segundo, a partir de nuestras teorías del aprendizaje moral. Probablemente, nadie pondría en este momento en tela de juicio la relevancia de la literatura, por ejemplo, en el aprendizaje moral. Por razones de índole aristotélica, aunque no sólo. Sin embargo, si podemos sensatamente sostener el valor de la literatura en la educación moral, y al mismo tiempo una noción de autonomía tal como la que estamos enjuiciando, es, en cierto modo, porque asumimos que quien aprende de la literatura ya sabe con anterioridad - al menos ha aprendido a hacer el movimiento de atribución de autonomía, y a juzgar moralmente (si no me instalo en el heterónomo suelo de la autenticidad)-. Aquí se integra la critica estándar del comunitarismo, a saber, el universalismo es una forma de particularismo - sólo si comparto ciertos puntos de vista en realidad me postulo como universalista, pero eso no frena el empuje del que no lo es-. En realidad transitar por este tipo de argumento es echar mano de una reductio ad absurdum. Dado que, efectivamente, no deseamos abandonar la idea de la relevancia moral de la literatura $-\mathrm{u}$ otras formas de manifestación de los que ya podría denominarse «la imaginación moral», como, por ejemplo, el cine, acaso - en los procesos de aprendizaje, se hará necesario revisar la noción de autonomía que convierte en problemático aceptar nuestro punto de partida.

\section{La imaginación moral y la filosofía o de la deconstrucción de la oposición autonomialheteronomía}

Pese a los argumentos aportados, podríamos sostener cierta idea de autonomía porque es imprescindible para elaborar una teoría moral. La creencia en el valor de la autonomía podría plausiblemente suponerse paralela o al menos semejante a la creencia en la capacidad del pensamiento reflexivo - léase filosofía- para hacer 
racional la vida, es decir, para organizar racionalmente la vida. Incluso podrían extrapolarse tal tipo de afirmaciones para llevarnos a suponer que la dicotomía autonomía/heteronomía es una herramienta filosófica (sólo) apta para sostener el carácter racional - esto es humano- de la existencia (humana).

Pero, para terminar, me gustaría acudir a un ejemplo que nos sirve como recordatorio o acaso como advertencia de las paradojas en que podríamos incurrir si tratamos de defender una idea de autonomía - opuesta a heteronomía - que, al mismo tiempo, nos justifique para hacer hincapié en el modo en que esta idea de autonomía garantiza nuestra identidad como seres racionales.

La historia de Don Quijote puede servir como una alegoría - una manera de hacer visible esto. La historia de Don Quijote suele leerse como una novela de tesis sobre lo malsano de incurrir en la locura - producto en este caso anecdóticamente de la mala elección de una literatura inadecuada. Pero la figura de Don Quijote nos ayuda también a plantear de nuevo la pregunta que señalábamos al comienzo: ¿por qué la heteronomía es peor, moralmente, que la autonomía? ¿Por qué no deseamos pensar al sujeto moral como heterónomo? Obviamente, lo que justifica la calificación de «loco» para Don Quijote es precisamente su presentación como absolutamente heterónomo.

El sujeto heterónomo es aquel que actúa de modo que sus acciones se consideran buenas en la medida en que se adecuan al estándar preestablecido; de ahí su falta de valor moral ${ }^{15}$.

Pero, en realidad, la historia de Don Quijote es un canto a la locura frente a la cordura. Si bien se mira, la locura es justamente lo contrario de aquello que representa Don Quijote: no seguir reglas racionales, desconocer el mundo y carecer de control. El Quijote deconstruye la oposición locu$\mathrm{ra} /$ cordura y es esto lo que lo convierte en relevante cognitiva y moralmente.
El miedo a la literatura es plausiblemente miedo a la heteronomía, y eso lo deconstruye irónicamente Cervantes haciéndonos ver que, en realidad, el sujeto heterónomo por antonomasia, Don Quijote, imbuido de las reglas de la caballería aprendidas de otros, en el fondo representa muy bien la unidad interna y la falta de fracturas que parece tan deseable desde la postulación de la autonomía. La figura cervantina efectivamente deconstruye el hiato entre autonomía/heteronomía. Si bien Don Quijote parece ser el ejemplo más pleno de sujeto heterónomo, también es cierto que ejemplifica en grado sumo lo que podríamos denominar la «irracionalidad de la certeza», o, en otras palabras, el sinsentido de la universalización de las reglas o su carácter rígido - cosas que se aproximan peligrosamente al deseable carácter categórico de los imperativos morales-.

Pasemos ahora a analizar un ejemplo filosófico bien conocido: el sujeto veraz kantiano. Si no me equivoco, una descripción ajustada del mismo lo asemeja enormemente a un loco quijotesco. Alguien incapacitado para percibir conflictos de valores o entre principios - por ejemplo, el principio de la veracidad y el de la compasión - es, en definitiva, un miope moral, un ciego ético ante las demandas del otro, un enajenado de la condición humana, demasiado preocupado por la conformidad consigo mismo y por la certeza acerca de su buen obrar.

No estoy, desde luego, tratando de sostener el carácter pernicioso de la lectura, sino simplemente que me interesa señalar las posibles consecuencias que cierto modo de interpretar el valor moral de la literatura -y probablemente no sólodesde presupuestos que exigen pensar en un sujeto autónomo puede curiosamente conducirnos a una situación paradójica.

En segundo lugar, si el paralelismo entre la capacidad para configurar racionalmente la vida y la oposición autono- 
mía/ heteronomía fuera un hecho, probablemente lo que se deduciría es que nuestra idea de agente moral autónomo, frente al desvalorizado sujeto heterónomo, no sería sino un nuevo ejemplo de engaño consolador, o, en su caso, un ejemplo de represión de lo que se temería fuera una forma de irracionalismo, en la tónica de la sospecha de que eso que denominamos racionalidad potencialmente esconde un engaño, deliberado o no, que de suyo podría pensarse útil para consolarnos (por la falta de sentido de la vida como tal).

De alguna manera, sobrevuela la amenaza de cierto escepticismo cuando tratamos de «atentar» contra la idea de un sujeto autónomo como garantía de una posición universalista. ¿Podríamos aspirar a la filosofía como correctivo escéptico? La filosofía nos obliga a una constante reconstitución reflexiva, nos convierte en sujetos plásticos, y ésa es la condición de todo aprendizaje. Sin embargo, el aprendizaje entendido así, para no caer en la inconsistencia, precisa de un mentor que controle la automodelación del discente. Pero la egregia figura socrática tiene el peligro de conducirnos a una regresión ad infinitum. Y no otra, sospecho es la razón de la postulación de la autonomía o de la autosuficiencia, y la necesidad de desvincularse las propias concretas contingencias de ese sujeto, para salvarse de los peligros del relativismo. De modo que la autonomía no es personal, en definitiva, sino abstracta y derivada del tipo de principios o imperativos que me puedo otorgar. Curiosamente se diría que la función de los relatos, de la literatura, es la función del mentor, un mentor plural. Los relatos también «cortan» la regresión ad infinitum. Porque son mundos exentos y comportan elementos normativos.

¿Cómo se lucha contra el relativismo o el escepticismo? Si no queremos hacernos cargo de un argumento trascendental hemos de recurrir a algo mucho más modesto que habría que tratar de describir así: frente a una especie de transparencia de los contextos o a su carácter abierto (Scanlon), hemos de tender a cerrar los contextos, a considerarlos en su totalidad, con la adicional «falta de competencia» que otorga su opacidad - y la nuestra, incidentalmente - . Porque la transparencia del contexto es un derivado de la universalidad del juicio y recíprocamente. Ser un sujeto moral exige la plasticidad de actuar en contextos opacos y cargar con ello y sus consecuencias.

\section{A la búsqueda de nuevas metáforas}

Como es sabido, los pragmatistas por necesidad deben darnos una versión del sujeto moral que no se asemeje en nada al sujeto de corte kantiano. Dewey, por ejemplo, nos ayuda a pensar que los filosofos que han tratado de distinguir tajantemente entre razón y experiencia o entre moralidad y prudencia sólo han confundido las cosas, al convertir una distinción de grado en una distinción metafísica ${ }^{16}$. El que podríamos denominar mito del yo moral (sin necesidades de cargarlo con el calificativo de «psicópata», como sí hace Rorty) obedece, a ojos de pragmatista, y no sólo, a la confusión que acabo de mencionar o acaso al miedo al error en las decisiones morales.

Pero nótese que, sin la posibilidad de equivocarse, una decisión no podría ser moral en buena lógica de acuerdo con la idea de autonomía. Es decir, el sujeto que se autogobierna y legisla en el mundo moral ha de tener abierta la posibilidad de errar, porque de lo contrario parecería no ser libre, sino estar determinado a acertar siempre.

Podemos en todo caso, y provisionalmente, quedarnos con dos críticas que emanan del pragmatismo y que son relevantes. En primer lugar, que la idea del yo verdadera es culpable de ciertos malentendidos cuanto menos en ética - la ansiedad del universalismo, la imposibilidad de 
hacer casar la moralidad y otras formas de relación como la simpatía o la compasión-. En segundo lugar, y como responsable de todo lo demás, que la necesidad, que arranca de Platón y culmina con Kant, de diferenciar apariencias y realidad, pasiones y razón, es decir, la necesidad de una fundamentación metafísica, produce la confusión de lo que constituye simplemente el desenvolvimiento evolutivo de una especie cada vez más compleja con algo de alguna manera dado.

Volvamos al problema de la autonomía. Recordemos que las descripciones que proporcionaba Hill estaban destinadas precisamente a resolver, quizás tímidamente, la aparente incompatibilidad entre una versión del sujeto moral como poseedor de la propiedad de la autonomía y las versiones de cuño humeano y también de tradición feminista, en las que priman la simpatía o la compasión, la confianza o el cuidado. Sin embargo, la apuesta de Hill adolece de nuevo, aunque algo paliado como explicaré, de las dificultades que se siguen de la consideración tradicional de la autonomía. Esencialmente, como veíamos, él propone una versión de la autonomía como autogobierno $\sin$ posibilidades de autofractura que supongan obstáculos. Esta versión cae del mismo lado que las otras en cuanto a un problema, al que precisamente atacan los pragmatistas, a saber, el carácter dado de tal autonomía, si bien, en su caso, podría preverse, pero queda sin especificar la posibilidad de una formación, de una educación. En efecto, sea entendida como una propiedad o como la atribución de un derecho, la autonomía entendida tradicionalmente viene dada, intrínsecamente o no, eso es igual. En ambos casos parece necesario hacerse partícipe de alguna creencia esencialista: si la autonomía es la propiedad de un sujeto responsable que se autolegisla, eso es así por su ser racional; si es un derecho que atribuyo al otro como sujeto responsable, al que asumo autolegislador es en virtud de eso o de su dignidad porque es un sujeto que se autolegisla, la circularidad está servida también.

La propuesta pragmatista apostaría en cambio, sin duda, por la plasticidad no sólo de las sociedades y de las prácticas - véase al respecto la metáfora del patchwork que utiliza Rorty-, sino también por la plasticidad del sujeto mismo. Obviamente en uno y otro caso hemos de acceder pensar en una pluralidad más o menos nivelada de prácticas, $o$ de creencias incluso, y en su carácter contingente.

Si nos fijamos detenidamente, la crítica inmediata que se puede oponer al pragmatista no difiere mucho de la que tendríamos que hacerle a quien propone una noción de autonomía «más limitada», como hemos visto. Y ésta no es otra que la apertura a la amenaza del relativismo. Un sujeto no auto-fracturado a la hora de enfocar problemas morales no tiene por qué ser semejante a otro ni adoptar el mismo tipo de máximas; precisamente sólo si aceptamos el carácter universal de una propiedad común a todos los miembros de una clase dada, por ejemplo, los seres racionales, evadimos el problema del relativismo. Con mayor razón, la plasticidad del sujeto y del mundo hace improbable pensar en salidas universalmente aceptables o aceptadas. El pragmatista probablemente diría que no es necesario en absoluto, pero, al mismo tiempo, se muestra muy optimista en la validez de su modo de presentación para construir una sociedad mejor moralmente. La manera «limitada» de entender la autonomía nos proporciona como mejor aportación la versión del sujeto como alguien que no necesariamente ha de adoptar un solo punto de vista desde una misma posición, sino como quien ha de jugar con diferentes registros no incompatibles - por ejemplo, el registro de los sentimientos de simpatía, o de compasión, y el registro de la atribución de derechos o sanciones, etc.- - sin embargo, no acaba de hacer explícito cómo eso no conlleva precisamente aquello que trata de negar, a 
saber, la falta de unidad interna en último extremo. El pragmatista, en cambio, trata de aportarnos una herramienta que sea útil a la hora de aportar sentido a la plasticidad del mundo y del sujeto, y ésa no es otra que la imaginación. El optimismo pragmatista, en palabras de Rorty de nuevo, no se manifiesta en la creencia o la apuesta por un progreso que se cifre en acercarse «a lo verdadero o a lo Bueno o a lo Correcto, sino como un incremento del poder de la imaginación» ${ }^{17}$. Descrita curiosamente como «el bisturí de la evolución cultural», la imaginación tiene como virtud «redescribir lo familiar en términos no familiares», cosa con la que habrían estado de acuerdo los románticos, sin duda, con el no menos curioso objetivo de «sustituir el conocimiento por la esperanza». Pero, ¿en qué sentido la imaginación - entendida como un miembro, ironías de la vida, de una plantilla de oposiciones, junto con la curiosidad y, del lado contrario, de la certeza y el orgullo, respectivamente-, es el bisturí de la evolución cultural? Un bis- turí corta, separa, saja, y la metáfora pragmatista es significativamente unitiva, es el patchwork. Un bisturí es también el utensilio necesario para la recomposición plástica de una cirugía reconstructora. Es verdad que el oficio del bisturí es siempre destructivo, separador, agresivo, pero también que sólo gracias a él es posible pasar a la labor subsiguiente de costura, y fundamentalmente es verdad que coser sin utilizar previamente el bisturí sería probablemente dejar las cosas como estaban, incapacitarse para dar un aire nuevo a lo viejo. Lejos de considerar la versión de Rorty la pirueta del ironista, quedémonos con lo que de ella se puede extraer: el sujeto y las sociedades poseen una cierta ansiedad de reconstituirse perpetua e indefinidamente, y ésa es su fuerza intelectual y también moral. La salida a cualquier forma de escepticismo radica en el movimiento constante de reflexión y reconstrucción ${ }^{18}$ - frente a la parálisis del escéptico e, incidentalmente, de cualquier forma de absolutismo.
'Autonomy and Self Respect, Cambridge University Press, 1992

2 Véase op. cit., p. 44.

${ }^{3}$ Véase op. cit., pp.46-47.

${ }^{4}$ «Accepting the right of a does not mean that we must accept more extreme views that are sometimes associated with the word a. For example, we can acknowledge the right without in any way implying that self-sufficiency, independence, and separation from others arte goals worth pursuing [...] Rights are just one aspect of complex moral problems, and fixation on this aspect to the exclusion of others can be as much a moral faults as overlooking rights altogether...», op. cit., p. 49

${ }^{5}$ Cambridge University Press, 1988.

6. Véase D. Hare, Moral Thinking, Oxford University Press, 1981.

${ }^{7}$ Como veremos, la mejor figura para representar tal cosa, que, por otra parte, es expresada en Los origenes del totalitarismo de Hannah Arendt, creo, con suficiente claridad, es Don Quijote y lo que vulgarmente ha hecho pensar. Es interesante el trabajo de Agustín Serrano de Haro, «Totalitarismo y filosofía», en Reyes Mate (ed.), La filosofia des pués del holocausto, Barcelona, Riopiedras, 2002. pp. 2-54.

${ }^{8}$ Según la distinción que establece Wittgenstein en su «Conferencia sobre ética» podemos utilizar el predicado «es bueno», característico de los juicios morales, en dos sentidos distintos que conviene mantene diferenciados. Por un parte, ese «es bueno» en un juicio como «x es bueno» es traducible por «x sirve a un propósito determinado», o «x satisface las expectativas de acuerdo con un objetivo predeterminador. A este modo de usar el predicado «es bueno» lo denomina Witgenstein el sentido «trivial» o «relativo». E otro sentido, que, a su vez, será denominado «ético» o «absoluto», no admite en cambio una traducción inmediata, si no es por vía negativa.

${ }^{9} \mathrm{P}$. Bruckner, La tentación de la inocencia, Barcelona, Anagrama, 1996.

${ }^{10}$ Se trata quizá de cambiar el punto de mira, pasar de centrarse en lo moral para hacerlo en lo ético pasar del terreno de las obligaciones al de los víncu- 
los o las demandas de los otros; de la moralidad privada a la moralidad pública, etc., tal como la entiende por ejemplo Robert Kane en Through the Moral Maze (1994): «Let us say that your private morality is "what you think is the right way to live, for yurself or anyone"; public morality is "what you owe others even if they do not agree with your private morality"» (p. 101). Es evidente que esta dicotomía plantea inmediatamente paradojas. Kane, no obstante, considera necesario establecerla así en sociedades plurales.

11 The inner citadel: essays on individual autonomy, editado por John Christman, Nueva YorkOxford, Oxford University Press, 1989.

${ }^{12}$ Apología de lo contingente, Valencia, Institució Alfons el Magnánim, 1995.

${ }^{13}$ En términos no morales, sino epistemológicos, podríamos referimos a esta misma posición como el prejuicio parmenideano. La unidad del pensamiento y el mundo, en otras palabras, la ausencia de rupturas o de distancia entre uno y otro son condición del conocimiento, porque nos aportan la verdad. Y, recordemos, es significativo la imagen de aquellos que, frente a quienes alcanzan la verdad, yerran o deambulan por el camino de la opinión: van bicéfalos.

${ }_{14}$ Christine Korsgaard, por ejemplo, presenta una tesis que podría suponerse anti-esencialista, en su intento de superar la «paradoja de la autoconstitución». Entiende la identidad en términos de un proceso autoconstitutivo de acuerdo con un estándar que es constitutivo y normativo al mismo tiempo desde una perspectiva funcional o teleológica. Si bien el sujeto se hace en sus acciones sin que ello presuponga un núcleo dado, el proceso incesante de autoconstitución se presenta en paralelo al proceso de «ser un buen $\mathrm{x}$, y se asume el paralelismo entre «virtuoso» y «saludable», porque, cito: «health is not, strictly speaking, goal for giraffes, but rather is our name for the inne condition which enables the giraffe to succesfully perform its function - which is to go on on being a giraffe. This parallels the way in which, as I said earlier, goodness is not a goal for people, but rather is our name for the inner condition which enables a person to successfully perform her function - which is to maintain her integrity as a unified person, to be who she is" (Self-Constitution: Agency, Identity, and Integrity, Locke Lectures, 2002, pp. 25-26).

Nótese que esta idea de la integridad como unidad interna va de la mano de una metáfora de no poco interés: es la metáfora del «lazo», lo que nos ata. Normalmente esta figura sirve para poner de relieve de modo inmediato que hay algo, por ejemplo principios de la razón práctica, tal como hace Korsgaard, que «nos atan», nos atan a nosotros mismos naturalmente. $\mathrm{Y}$ que eso, por ejemplo, constituye un modo más de expresar lo que es efectivamente nuestra identidad como sujetos morales. ¿Por qué esta metáfora no es utilizada para señalar una atadura externa, con los otros, con los usuarios de un lenguaje común por ejemplo? es una pregunta que merecería alguna reflexión.

${ }^{15}$ La pregunta es si afirmar esa diferenciación nos conduce a sostener que el valor cognitivo-moral adscrito a la literatura ( a la filosofía también?) es sólo relevante como un aprendizaje que nos permite producir juicios de valor en un sentido «relativo» o «trivial». Quizá podríamos extrapolar de esto que ta aprendizaje sólo es útil para construir(nos como) sujetos heterónomos, en la medida en que cualquier juicio de valor acerca de nuestras acciones o las acciones de otros se ajustará al esquema señạado más arriba - «x es bueno» significa « $\mathrm{x}$ es adecuado de acuerdo con $\mathrm{el}$ objetivo $O$ predeterminado»-.

16 R. Rorty, ¿Esperanza o conocimiento?: una introducción al pragmatismo, México, Fondo de Cultura Económica, 1997, p. 81

17 Ibid., p. 100

${ }^{18}$ La mejor manera de entender esto es contemplar la pregunta: ¿En qué sentido es mejor decidir reflexivamente, filosóficamente, que seguir reglas? (Deliberación/norma).

Mi respuesta se basa en el carácter resistente de la filosofía, y de la deliberación moral por ello, frente a la blandura o a la tibieza del sentido común y a la claridad de la norma establecida. En otras palabras, el carácter resistente de la deliberación, de la reflexión nos obliga a crecer, a ser otros, mientras que la facilidad y la claridad de las normas nos mantiene en el mismo estado de infancia perpetuamente. Tras una u otra manera de entender las cosas se esconde una u otra manera de postular al sujeto - un sujeto plástico reflexivamente frente a un sujeto estático; un sujeto opaco, por otra parte, frente a un sujeto transparente desde el punto de vista moral-

Si digo que la deliberación o la reflexión o el argumento filosófico ofrecen resistencia, ello pretende indicar que en todos ellos se da un enfrentamiento con el problemático ser de las cosas y de las normas mismas. ¿Por qué resistente? Creo que por dos tipos de razones, o al menos se puede tratar de explicar desde dos tipos de enfrentamiento diferentes: porque el argumento o la deliberación moral no se deja atrapar de manera inmediata y completa; en segundo lugar, porque el sujeto que se enfrenta al argumento a la deliberación y participa en ella tampoco se deja engatusar inmediatamente ni en consecuencia puede mimetizar formas de vida propuestas por el curso de la deliberación moral inmediatamente. El sujeto que argumento o delibera no es el sujeto de una representación cerrada, sino un agente activo por ello y que se transforma conforme se transforma el argumento o deliberación en curso. Y subrayo en curso. 